\title{
Discussion on the Risk and Supervision Path of Internet Financial P2P Network Loan Model
}

\author{
Dielin $\mathrm{He}$
}

School of Accounting, Zhongnan University of Economics and Law, Wuhan Hubei, 430073, China

Key words: Internet finance, P2P network credit model risk, Regulatory measures.

\begin{abstract}
In the context of Internet finance, the application of P2P network credit model has been paid more and more attention. However, during the practical application, there are more operational risks and it is difficult to improve the security of financial lending mode. Therefore, during the practical application, the relevant departments must do a good job of risk supervision, innovative work methods, improve their own quality of work, optimize its development system, to achieve the desired regulatory objectives.
\end{abstract}

\section{Introduction}

In the actual application of Internet financial P2P mode, the relevant management personnel must do a good job of supervision, the timely detection of the existence of risk issues, and take effective measures to standardize the risk to ensure that it can improve its efficiency and quality of work.

\section{Internet Financial P2P Model Concept}

Internet finance, mainly is the traditional financial industry into the Internet, establish the correct spirit of the Internet, the formation of new financial areas. In terms of broad terms, all financial services with Internet spirit can be collectively referred to as Internet finance. In theory, as long as the financial involved in the Internet system, you can call it Internet finance, such as: online payment model, Internet financing model, all belong to the modern Internet financial model.

For P2P reception, the main is the construction of a dedicated network lending platform, that is, third-party companies, are intermediary systems, can provide lending services to borrowers. For financial and interest rates and other data information, belonging to the investors to the relevant borrower loans, can enhance its economic benefits. In the process of actual development, P2P network lending platform is a combination of modern network lending and financial services station results. In 2005, the world's first P2P network financial platform has made some construction results, on-line location for the New York area. In 2015, P2P lending model in the 10 years of development, has been the Chinese people's attention, the volume of transactions in the gradual growth, and can enhance the economic benefits of various intermediate platforms for the borrower to bring more convenience, Gradually enhance its development effect.

\section{The Operational Concept of Internet Financial P2P Loan Model}

In the traditional private lending, the process is more cumbersome, and approval requirements are higher, it is difficult to improve the efficiency of borrowing. After applying P2P network borrowing model, it can improve its work convenience and reduce the transaction information and transaction cost, broaden the scope of borrowers and lenders, and diversify the concentration risk of investors. Under normal circumstances, P2P network credit model of the application process mainly includes the following: 
First, the borrower in the relevant platform to register their own information, which the authenticity of the various types of information need to comply with the relevant provisions, such as: ID card information, personal experience information, etc., at the same time, the lender also registered in the network to ensure that credit Work safety.

Second, the relevant platform will be based on various types of information and data, the borrower to rate processing, and according to the actual situation of the rating to carry out related activities.

Third, the borrower will be in the network platform to publish relevant information, such as: loan amount information data, loan period information data, loan interest rate information data, in order to facilitate lending activities.

Fourth, the relevant lenders can be based on risk preferences and other timing, a clear project bidding situation, and comprehensive risk control work in order to facilitate the processing of various types of information data.

Fifth, after some process, the borrower will obtain the relevant loan success information data.

Sixth, the borrower after approval, will receive the relevant amount of loans.

Seventh, the borrower within the prescribed period, the return of the loan to ensure that the relevant provisions can be met.

Eighth, the lender within the prescribed period, will recover the principal and interest of loans in order to facilitate the relevant work.

\section{Risk Analysis of P2P Network Loan Model}

Although China has begun to use P2P network credit model, and various types of business to standardize the treatment, but in practice, there are still more risk problems, it is difficult to improve the application of credit model effect, and even bring people a certain economy loss.

\section{Credit risks}

For the P2P network credit model, there will be a lack of transparency in the borrower's information and the low level of operation of the platform during the practical application. It is difficult to improve the running level of the model and improve the quality of the mode application. Specific performance for the following:

First, the borrower's information is less transparent. In the relevant platform, the borrower to provide the amount of information is very small, although some platforms have developed a perfect borrower certification system, requiring all kinds of information into the system, you can better verify the borrower information. However, for the relevant platform and the lender, can not better understand the borrower or the enterprise's asset information, can not reflect the actual situation of cash flow, it is difficult to fully understand the borrower's personal real information, the lack of for the borrower's Understand, cause risk problems. At the same time, the lender is difficult to obtain the borrower from the network of real information, and even fraud risk phenomenon, coupled with some of the borrower's repayment ability has not yet mastered, once due to personal factors or family factors can not repay, Will bring more risks, affecting the platform or the economic benefits of the lender.

Second, the platform management and management quality is low. First of all, the platform access threshold is low, for the funding requirements are very low, can not build high-quality personnel, it is difficult to improve the quality of management work, can not improve the platform's risk resistance, affecting the effectiveness of network lending work. For example: the public network in the actual development, only listed 28 days has been off the assembly line, mainly because of its registered capital less, not even reached 9 million yuan, and after the registration of industrial and commercial registration of the relevant funds have been taken out, The balance of the book is even less than 100 million, at the same time, the relevant management departments of the network of knowledge on the lack of knowledge, did not establish the correct concept of risk control, it is difficult to enhance its work results. Secondly, in the actual management of the relevant platform, the compensation for the default loan requirements are lower, the borrower appears to default phenomenon, the lender blindly 
rely on the P2P platform for its liquidated damages to recover, can not carry out the relevant work, or even Will affect the economic benefits of the lender, it is difficult to enhance the operational level of the platform. Finally, some platforms have not developed a sound risk compensation system, can not use all kinds of security, etc., to reduce the risk of which there, can not enhance its transparency.

\section{Information technology risk}

In the actual management of the platform, for business and data storage and so more dependent on the construction of hardware and software systems, but in the system management, often because of some viruses and other issues, personal information theft and tampering phenomenon Suffered serious economic losses. At the same time, some of the technology into the poor results, can not use technology to enhance the platform to run the security and stability, and even there will be some difficult to solve the problem.

\section{Operational risk dangers}

The management of the platform lack of relevant professional knowledge, did not grasp the advanced service skills, in the course of business operations, can not accurately find the risk point, can not use advanced technology to prevent it, it is difficult to do internal control work, can not Establish the correct management concept. During the actual operation, the management staff for internal control and other management processes are not familiar with, the lack of a certain work experience, resulting in risk management confusion. At the same time, some managers of the professional ethics of poor, for their own interests, damage to the economic benefits of lenders [1].

\section{Legal risk}

Because of the lack of external supervision and management of P2P network borrowing platform, there are often illegal phenomena such as forging information of borrowing, misappropriation of related funds and so on. Some staff members may even illegally absorb deposits and so on. For example: the company in the P2P network lending business process, there have been illegal operation of the phenomenon, the borrower suffered serious economic losses. Another example: Taobao on behalf of the management staff is a graduate college students, the use of false loans, etc., the relevant funds into the individual account, trying to take money absconded [2].

\section{Reputation risk}

In the P2P network lending platform, due to poor operating capacity, it is difficult to resist all kinds of risks, resulting in reduced media reputation, coupled with some public negative public opinion, the platform suffered a certain blow, can not enhance people's trust, To meet their future development needs.

\section{An Analysis of the Regulatory Approaches to the Internet Financial P2P Network Borrowing}

In the Internet financial P2P network lending mode of operation and management, the relevant departments need to conduct a comprehensive supervision and management, to avoid the existence of various types of risk problems, reduce the economic loss of lenders, improve their credibility and so on. Specific measures include the following:

\section{Establish the correct spirit of innovation}

In the process of network lending mode management, the relevant personnel need to analyze the combination of the Internet and the financial industry development requirements, inherit the good way of civil loans, and enhance the borrower model of advanced nature and convenience to meet the needs of borrowers. For the supply of funds, etc., can promote the long-term progress of small businesses to meet the individual's consumer demand, enhance the flexibility of entity enterprises. In the meantime, we must establish the correct concept of innovation, for its actual development needs, 
innovative business methods and management forms, in order to carry out online lending activities [3].

\section{Strengthen external supervision efforts}

In the P2P network lending mode of operation and management, often there are risks, we must strengthen the external supervision efforts, adjust the relationship between external and internal, and promote the healthy development of the industry. First of all, the relevant departments need to clear regulatory functions and their own regulatory scope, and develop targeted work program to enhance the quality of their work. Second, the relevant departments need to develop sound regulatory regulations, a clear industry access conditions, and for the exit of the industry to conduct a comprehensive supervision and management to enhance the quality of their work. For example: the development of specialized P2P network lending model of financial license management system, requiring the relevant industries to handle various types of licenses, so that it is toward the regularization and high management level of progress. Finally, in the external supervision work, we need to clear the responsibility of the regulatory body, the construction of advanced regulatory programs, the use of legal provisions to do a good job punishing work to enhance the reliability of their work to achieve the desired regulatory purposes [4].

\section{Increase publicity efforts}

Relevant departments need to vigorously promote the financial knowledge, so that people can establish the correct awareness and enhance the effectiveness of risk control, such as: the creation of "financial knowledge publicity" and other activities for people to explain all kinds of financial business knowledge, and asked the borrower a comprehensive understanding Their own responsibility to form a certain form of information disclosure, in order to improve the quality of their work. At the same time, the relevant regulatory authorities should also develop a sound complaint mechanism to provide users with complaints channels, the timely detection of the financial industry for the impact of consumers, and safeguard the legitimate rights and interests of consumers in order to avoid the financial industry bad behavior [5].

\section{Avoid credit risk}

In the P2P network lending mode of operation and management, the need to develop a sound credit risk aversion model to enhance the operational safety of the system to reduce the risk of the existence of the problem.

First, you need to ensure the transparency of user information. After the borrower sends out the borrowing information, the relevant departments need to fully understand their actual situation, including: family life status, work situation, business situation, personal credibility and repayment ability, after understanding personal information, to its To review and approve. At the same time, but also to ensure that the borrower at any time to view the borrower's information data, and its comprehensive analysis to reduce the lender in the network platform in the economic losses.

Second, to enhance the management level. P2P network credit platform management, the need to develop a sound management system to reduce all kinds of credit risk. On the one hand, the need to build high-quality management personnel, its professional knowledge and advanced skills training, to master the relevant forms of management work to enhance the platform management and management of water products. On the other hand, in the process of platform management, the relevant departments need to strictly require the amount of funds, after the company listed, must have sufficient operating funds, and develop risk planning program in order to enhance its development effectiveness.

\section{Attention to the investment of science and technology}

Relevant departments need to increase investment in science and technology, establish a correct concept of innovation, in the actual management, you can invest enough funds, and the use of science and technology management system to avoid the theft of information systems and tampering behavior, 
efforts to complete the risk control tasks, And gradually improve their own work quality and reliability, to achieve the desired management purposes.

\section{To create a favorable environment for development}

In the case of strengthening the supervision work, the various departments and institutions need to cooperate with each other, for the financial industry to create a good Internet environment, so that it can be better development. For example: for the Internet P2P lending platform to build the central bank credit system, or the borrower's identity system, so that it can directly into the relevant system, the exact search for the borrower's real information in order to maintain the legitimate rights and interests of the lender and the platform The

\section{Conclusions}

In the actual development of Internet financial P2P network lending mode, the relevant departments need to develop a sound risk management program, build high-quality personnel, put enough funds to run, lay the foundation for its healthy and sustainable development.

\section{References}

[1] Wang Guoliang. Internet financial P2P network lending model of the risk and regulatory path, Technology horizon, 2013 (25): 297-298.

[2] Sun Chu. Internet financial P2P network lending model on the impact of traditional Chinese finance under background of “One belt one road”, Business economy, 2016 (1): 140-142.

[3] He Miao. Internet financial P2P network lending model and risk analysis, Huazhong University of Science and Technology, 2015.

[4] Xiao Manjun, Ou Yuyuan, Li Ying et al. Empirical Study on the Influencing Factors of Credit Risk in P2P Network in China, Journal of Finance and Economics, 2015 (1): 2-6.

[5] Guo Rengui .P2P network loan credit mechanism: model, problem and optimization, Southern Finance, 2016 (12): 97-101. 